\title{
Complications of Adenotonsillectomy in Children Under 3 Years of Age
}

\author{
Brian J. Wiatrak, MD, Charles M. Myer III, MD, and Thomas M. Andrews, MD
}

\begin{abstract}
Adenotonsillectomy in children may be performed safely on an outpatient basis in the majority of cases without an increase in complication rates. However, very young children comprise a unique patient subpopulation with regard to adenotonsillar surgery. Surgical indications in older children tend to be dominated by chronic recurrent infections, whereas younger children usually require surgery for chronic upper airway obstruction related to adenotonsillar hypertrophy. This study was undertaken to evaluate the adenotonsillectomy patient population under 3 years of age. Complication rates related to airway problems, hemorrhage, and dehydration were determined. Children under 3 years of age demonstrated an increased incidence of postoperative airway complications, manifested by oxygen desaturation and transient upper airway obstruction. It is recommended that adenotonsillectomy be performed on such patients on an inpatient basis with close postoperative monitoring including pulse oximetry. AM J OTOLARYNGOL 12:170-172. Copyright (C) 1991 by W.B. Saunders Company
\end{abstract}

Key words: adenotonsillectomy, complications, children.

The low rate of complications associated with adenotonsillectomy in children is well documented in the literature. As an outpatient procedure, adenotonsillectomy in children has been widely reported and is advocated by numerous investigators. ${ }^{1-4}$ The few publications concerning adenotonsillectomy in children under 3 years of age report complication rates similar to those of older children..$^{5-7}$ This conflicts with our experience at the Children's Hospital Medical Center in Cincinnati, $\mathrm{OH}$.

At this institution, the primary indication for adenotonsillectomy in the majority of patients under 3 years of age is airway obstruction due to adenotonsillar hypertrophy. Postoperatively, these very young patients are routinely admitted for monitoring due to their increased risk of postoperative airway complications.

A retrospective study was undertaken analyz-

Received September 14, 1990, from the Department of Otolaryngology, Section of Pediatric Otolaryngology, University of Michigan, Ann Arbor, MI; and the Children's Hospital Medical Center, Cincinnati, OH. Accepted for publication January 9, 1991.

This paper was a poster presentation at the Annual Meeting of the American Society of Pediatric Otolaryngology, May 1990.

Address correspondence and reprint requests to Brian J. Wiatrak, MD, 2451 Taubman Center, Box 0313, 1500 E Medical Center Dr, Ann Arbor, MI.

Copyright $\mathbb{C} 1991$ by W.B. Saunders Company

0196-0709/91/1203-0002\$5.00/0 ing postoperative adenotonsillectomy complications in patients under 3 years of age. Specific recommendations are made with regard to the postoperative care of patients in this age group.

\section{DEFINITION OF COMPLICATIONS}

The three major complications encountered in our study are defined as follows:

\section{Airway Complications}

1. Oxygen desaturation below $90 \%$ requiring any combination of supplemental oxygen, placement of a nasopharyngeal airway, or endotracheal intubation.

2. Postoperative obstructive apnea, manifested by a cessation of airflow in the presence of respiratory muscle activity for periods greater than 10 scconds.

3. Postoperative central apnea, manifested by a cessation of respiratory airflow for periods greater than 10 seconds with no observable respiratory muscle activity.

\section{Hemorrhage}

1. Immediate: within 24 hours of surgery.

2. Delayed: after 24 hours of surgery.

\section{Dehydration}

1. Inadequate oral intake after discharge requir- 
ing readmission to the hospital for intravenous hydration.

\section{MATERIALS AND METHODS}

The charts of 200 consecutive patients under 3 years of age who underwent adenotonsillectomy at Children's Hospital Medical Center of Cincinnati between January 1,1985 , and December 31, 1989, were reviewed. All adenotonsillectomies were performed by electrocautery and there was minimal blood loss in all cases $(<25 \mathrm{~mL})$. The cases analyzed involved no associated medical conditions. Patients with tracheotomy, laryngotracheal stenosis, or other airway abnormalities were excluded from the study. The age distribution of our patients and the indications for surgery are recorded in Table 1.

Fourteen patients were under 1 year of age, 42 patients were between 1 and 2 years, and 144 patients were between 2 and 3 years. A total of 125 patients underwent surgery for airway obstruction. Many patients had symptoms of obstructive sleep apnea, but routine sleep studies were not obtained. Seventy-five patients underwent surgery for chronic recurrent tonsillitis, defined as six or more episodes of acute tonsillitis within 1 year, or four or more episodes of tonsillitis per year for 2 years. Of the 125 patients who underwent adenotonsillectomy for airway obstruction, 13 were under 1 year of age, 25 were between 1 and 2 years, and 84 were between 2 and 3 years. Of the 75 patients who underwent surgery for chronic recurrent infections, one patient was under 1 year of age, 14 patients were between 1 and 2 years, and 60 patients were between 2 and 3 years.

Table 2 demonstrates the postoperative complications in our patients. A total of 25 patients $(12.5 \%)$ had complications after adenotonsillectomy. Of these, 14 had airway complications, eight suffered from dehydration, and three had postoperative hemorrhage. As seen in Table 2, the patients with airway complications are distributed similarly among the three age groups. Two of the four patients under 1 year of age required postoperative endotracheal intubation due to postoperative central apnea. Both of these patients were extubated successfully within 3 days. Two patients in the 2- to 3-year-old age group required postoperative endotracheal intubation for a period of 1 to 2 days for obstructive apnea. Both were successfully extubated. The remaining 10 patients who had airway complications suffered postoperative oxygen desaturation or episodes of postoperative obstructive apnea. A nasopharyngeal airway and supplemental oxygen were applied successfully in all of these cases. These data are summarized in Table 3.

The average hospital stay for patients in the airway complication group was 3.5 days (range, 1 to 7 days). The three patients who suffered delayed tonsil hemor-

TABLE 1. Indications for Adenotonsillectomy

\begin{tabular}{|c|c|c|c|}
\hline AcE & $\begin{array}{c}\text { Airway } \\
\text { OBSTRUCTION }\end{array}$ & $\begin{array}{c}\text { RECURRENT } \\
\text { ADENO- } \\
\text { TONSILLITIS }\end{array}$ & $\begin{array}{c}\text { Total } \\
\text { No. of } \\
\text { Patients }\end{array}$ \\
\hline Under 1 yr & 13 & 1 & 14 \\
\hline 1 to $2 \mathrm{yr}$ & 28 & 14 & 42 \\
\hline 2 to $3 \mathrm{yr}$ & 84 & 60 & 144 \\
\hline Total & 125 & 75 & 200 \\
\hline
\end{tabular}

TABLE 2. Postoperative Complications $(N=200)$

\begin{tabular}{lcclc}
\hline \multicolumn{1}{c}{ AGE } & AIRWAY & $\begin{array}{c}\text { Dehy- } \\
\text { DRATION }\end{array}$ & $\begin{array}{c}\text { Hemor- } \\
\text { RHAGE }\end{array}$ & Total \\
\hline Under 1 yr & 4 & 0 & 0 & $4(2 \%)$ \\
1 to $2 \mathrm{yr}$ & 5 & 1 & 0 & $6(3 \%)$ \\
2 to $3 \mathrm{yr}$ & 5 & 7 & 3 & $15(7.5 \%)$ \\
Total & $14(7 \%)$ & $8(4 \%)$ & $3(1.5 \%)$ & $25(\mathbf{1 2 . 5 \% )}$ \\
\hline
\end{tabular}

rhage were admitted for an average of 1.6 days and the patients in the dehydration group were admitted for an average of 2.2 days.

Of the patients in the tonsil hemorrhage group, one patient was an immediate tonsil bleed, requiring an extra day of admission. The two other patients suffered delayed hemorrhages. Only the patient with an immediate tonsil hemorrhage had to return to the operating room for control of the bleeding, which was performed with suction cautery. All hemorrhage patients were in the 2- to 3-year-old age group.

There were eight patients in the dehydration group. One was in the 1 - to 2 -year-old age group, while the remaining seven were in the 2 - to 3 -year-old age group. No patients under 1 year of age required admission for dehydration.

\section{DISCUSSION}

The literature regarding adenotonsillectomy often focuses on the question of inpatient versus outpatient surgery. It has been demonstrated in numerous published reports that adenotonsillectomy may be performed in children on an outpatient basis with a low complication rate. ${ }^{1-4}$ Outpatient adenotonsillectomy in appropriate cases is rapidly becoming the standard of care in the medical community. However, there are criteria for performing surgery on an inpatient basis, including concurrent medical problems, a history of obstructive sleep apnea, and a patient who lives in a remote area. Many institutions also regard children under 3 years of age as candidates for inpatient adenotonsillectomy, presuming an increased incidence of postoperative complications. Very few reports exist in the literature evaluating the complications of adenotonsillectomy, and specifically analyzing patients under 3 years of age. Helmus ${ }^{5}$ reported a very low complication rate in adenotonsillectomy patients under 3 years of age. All of the children in his study underwent surgery for chronic recurrent infections, and there were no documented cases of preoperative airway obstruction or sleep apnea. Richmond et $\mathrm{al}^{6}$ reported a higher incidence of postoperative airway complications in very young children. They specifically noted that patients undergoing adenotonsillectomy for airway obstruction had a higher incidence of postoperative airway complications than patients undergoing surgery for chronic recurrent infections. This study, however, comprised children of all ages. Berkowitz and $\mathrm{Zalzal}^{7}$ 
TABLE 3. Postoperative Airway Complications $(N=200)$

\begin{tabular}{|c|c|c|c|}
\hline $\mathrm{AGE}$ & $\begin{array}{l}\text { POSTOPERATIVE } \\
\text { ENDOTRACHEAL } \\
\text { INTUBATION }\end{array}$ & $\begin{array}{c}\text { NASOPHARYNGEAL } \\
\text { AIRWAY-SUPPLEMENTAL } \\
\text { OXYGEN }\end{array}$ & $\begin{array}{l}\text { Total No. } \\
\text { of Patients }\end{array}$ \\
\hline Under $1 \mathrm{yr}$ & 2 & 2 & 4 \\
\hline 1 to $2 \mathrm{yr}$ & 0 & 5 & 5 \\
\hline 2 to $3 \mathrm{yr}$ & 2 & 3 & 5 \\
\hline Total & $4(2 \%)$ & $10(5 \%)$ & $14(7 \%)$ \\
\hline
\end{tabular}

reported a complication rate of $10.5 \%$ in 190 children under 3 years of age undergoing adenotonsillectomy for airway obstruction. They concluded that age should not be a factor in the decision to operate on very young children.

Our data suggest that the most common indication for adenotonsillectomy in children under 3 years of age is airway obstruction manifesting as loud snoring and obstructive sleep apnea. The overall complication rate (bleeding, dehydration, and airway) in our series is similar to those reported previously in older age groups undergoing adenotonsillectomy $(12.5 \% \mathrm{v} 14 \%)^{8}{ }^{8}$ However, the vast majority of complications in this very young group are related to airway obstruction, whereas rates of postoperative bleeding and dehydration are similar. Four of our patients required endotracheal intubation, with an additional 10 patients requiring placement of a nasal airway and supplemental oxygen. Seven of the 11 patients who suffered non-airway complications underwent adenotonsillectomy for chronic recurrent infections. Of the 18 patients who underwent surgery for airway obstruction and suffered complications, only four were non-airway related. This suggests that children under 3 years of age constitute a unique group different from older children in terms of indications for surgery and postoperative complications.

We offer the following recommendations for the postoperative management of adenotonsillectomy patients under 3 years of age. First, the procedures should be performed on an inpatient basis. The indication for surgery in the majority of these patients is adenotonsillar hypertrophy with airway obstruction, and the incidence of airway-related complications is higher in this age group. Second, postoperative monitoring of these patients should be performed in such a way that evidence of airway obstruction can be detected quickly. We feel strongly that monitoring should include pulse oximetry to provide early warning of oxygen desaturation. Unfortunately, these units are not easily obtained in all institutions. The involved nursing staff must be able to manage patients with poten- tial airway problems. In addition, resuscitation equipment such as laryngoscopes, nasal airways, endotracheal tubes, and self-inflating ventilation bags should be immediately available in case of acute airway obstruction or respiratory arrest. Although this study reviewed only patients under 3 years of age, any older child with a significant history of airway obstruction, determined by clinical history, physical examination, or preoperative sleep study, should be managed in the same manner.

The majority of patients under 3 years of age undergo adenotonsillectomy to relieve airway obstruction. According to our retrospective study, the overall complication rate in these children is similar to that in older children; however, their percentage of airway-related complications is higher. Children undergoing adenotonsillectomy for chronic recurrent infections are less likely to have airway complications postoperatively. Adenotonsillectomy in this age group should be performed on an inpatient basis with close postoperative monitoring including the use of pulse oximetry.

\section{References}

1. Shott SR, Myer CM III, Cotton R'T: Efficacy of tonsillectomy and adenoidectomy as an outpatient procedure: A preliminary report. Int J Pediatr Otorhinolaryngol 1987; 13:157163

2. Guida RA, Mattucci KF: Tonsillectomy and adenoidectomy: An inpatient or outpatient procedure? Laryngoscope 1990; 100:491-493

3. Haberman RS II, Shattuck TG, Dion NM: Is outpatient suction cautery tonsillectomy safe in a community hospital setting? Laryngoscope 1990; 100:511-515

4. Helmus C, Grin M, Westfall R: Same-day-stay adenotonsillectomy. Laryngoscope 1990; 100:593-596

5. Helmus C: Tonsillectomy and adenoidectomy in the one and two year old child. Laryngoscope 1979; 89:1764-1771

6. Richmond KH, Wetmore RF, Baranak CC: Postoperative complications following tonsillectomy and adenoidectomyWho is at risk? Int J Pediatr Otorhinolaryngol 1987; 13:117-124

7. Berkowitz RG, Zalzal GH: Tonsillectomy in children under three years of age. Arch Otolaryngol Head Neck Surg 1990; 116:685-686

8. Paradise JL, Bluestone CD, Bachman RZ, et al: Efficacy of tonsillectomy for recurrent throat infections in severely affected children: Results of parallel randomized and nonrandomized clinical trials. N Engl J Med 1984; 310:674-683 